OPEN ACCESS

Edited by:

Tingting Zhang,

Dalian University of Technology, China

Reviewed by

Peng Zhang,

National Natural Science Foundation

of China, China

Neven Ukrainczyk,

Darmstadt University of Technology,

Germany

*Correspondence:

Wenjing Song

soubunnsei@foxmail.com

Specialty section:

This article was submitted to

Structural Materials,

a section of the journal

Frontiers in Materials

Received: 08 October 2021

Accepted: 22 November 2021

Published: 26 January 2022

Citation:

Zhu X, Guo Z, Yang $W$ and Song $W$ (2022) Durability of Concrete With Coal

Gasification Slag and Coal Gangue Powder.

Front. Mater. 8:791178.

doi: 10.3389/fmats.2021.791178

\section{Durability of Concrete With Coal Gasification Slag and Coal Gangue Powder}

\author{
Xiaoliang Zhu ${ }^{1}$, Zhaoheng $\mathrm{Guo}^{2}$, Wen Yang ${ }^{3}$ and Wenjing Song ${ }^{1 *}$ \\ ${ }^{1}$ China Western Construction Academy of Building Materials Co., Ltd, Chengdu, China, ${ }^{2}$ School of Materials Science and \\ Engineering, Southeast University, Nanjing, China, ${ }^{3}$ China West Construction Group Co., Ltd, Chengdu, China
}

Lack and quality decrease of supplementary cementing materials (SCMs) such as fly ash and granulated blast-furnace slag is increasingly prominent in China. Thus, the use of coal gangue (CG) and coal gasification slag (CGS) as SCMs in concrete attracted more researcher's attention. This paper investigated the mechanical strength, porosity, and durability of CG-and CGS-added concrete. Experimental results showed that the activity of the treated $C G$ and CGS is better than that of ordinary mineral SCMs, indicating that CG and CGS concrete can satisfy the requirements of ordinary construction under reasonable processing technology. Both CG-added and CGS-added concrete illustrated better chloride penetration resistance. The aluminum element contained in CG and CGS causes the $\mathrm{C}_{3} \mathrm{~S}$ hydration to generate ettringite which is an erosion product under sulfate erosion, and it will intensify the damage of sulfate erosion. After 125th freezethaw cycles, the CGS-added concrete has no obvious failure which indicates that CGSadded concrete has great capacity in the frost resistance.

Keywords: coal gangue, durability, coal gasification slag, compressive strength, supplementary cementitous material

\section{INTRODUCTION}

Concrete is the most used material in construction and building engineering. Supplementary cementing materials (SCMs) such as fly ash (FA) and granulated blast-furnace slag (GGBS) are also used in the concrete systems to reduce the use dosage of cement (Kaur et al., 2012; Cyr, 2013), and durability of concrete is increased when high-quality SCMs were used in suitable dosage (Borosnyói, 2016; Lollini et al., 2016; Rahla et al., 2019).

In recent years, lack and quality decrease of SCMs such as fly ash and granulated blast-furnace slag are increasingly prominent, which directly affected the performance of concrete (Purebase, 2021). Low-quality SCMs in cement-based materials would lead to the slow strength development, weak durability, and service life of concrete (National Precast Concrete Association, 2010). The permeability will increase due to the slow pozzolanic reactivity and insufficient curing time of SCM-added cementitious materials, which promoted the diffusion of the harmful ions and thus aggravated the durability problems. The study by Gao et al. showed the larger water-soluble $\mathrm{SO}_{4}{ }^{2-}$ content in concrete under sulfate attack because of the high content of porosity and defects (Gao et al., 2017). Thus, research and development of other new SCMs was needed in the concrete area.

Coal gangue (CG) and coal gasification slag (CGS) contain a large amount of siliceous and aluminous minerals and have certain pozzolanic reactivity. In recent years, the use of CG and CGS as SCMs in concrete attracted more researcher's attention. Wang et al. studied the effects of CG 


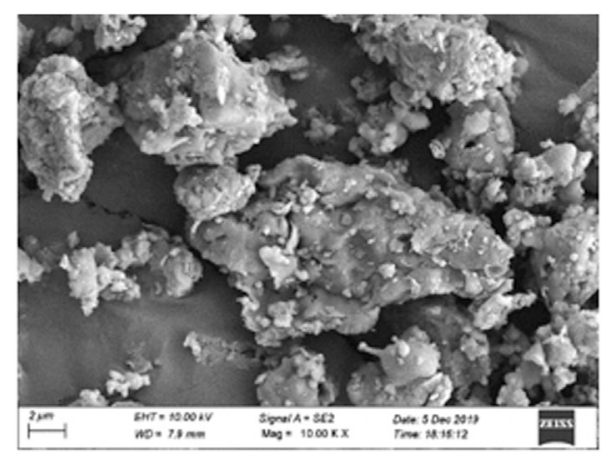

Calcined coal gangue

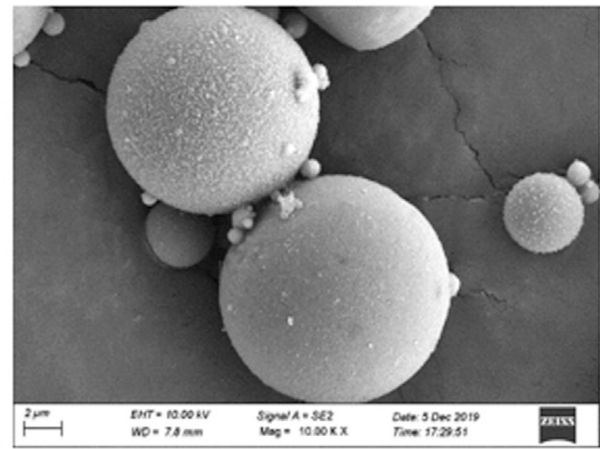

Fly ash

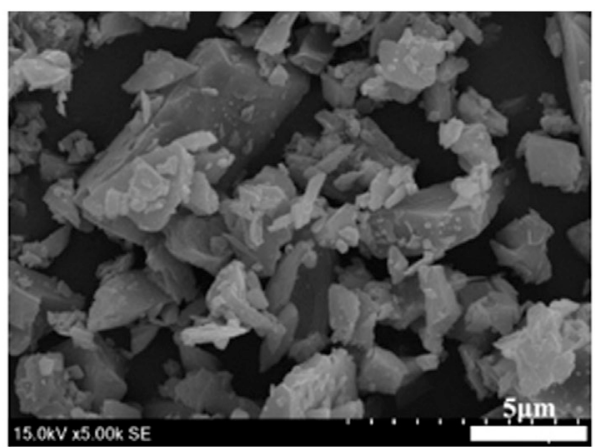

Coal gasification slag

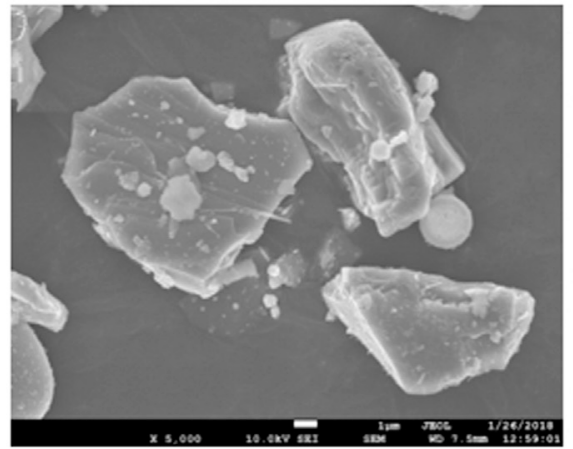

Granulated blast-furnace slag

FIGURE 1 | SEM image of raw materials.

with different fineness $(200,325,500,1250$, and 2000 mesh) on the mechanical properties, frost resistance, and chloride penetration resistance of concrete (Wang et al., 2020). Zhou using CG powder partially replaces Portland cement (PC) at 10, 20,30 , and $40 \%$ by weight for the blended cement paste mixes, and observes the degree of reaction of calcined coal gangue powder (Zhou, 2009). Pomykala proved the possibility of using slag from gasification of coal as a component of concrete and binding mixtures (Pomykała, 2014). Luo et al. investigated the influence of CGS on the fluidity of cement mortar as the admixture, which shows conducive to the fluidity (Luo et al., 2021).

At present, most of the research is mainly focused on the mechanical properties of coal gangue and coal gasification slag powder; for its application in cement-based materials, there are few studies on its impact on durability. As we all know, when concrete is used in engineering, it needs to meet not only mechanical properties, but also durability. Therefore, in order to make up for the lack of scientific research on the durability of coal gangue and coal gasification slag and promote the application of coal gangue and coal gasification slag in concrete, this paper studies the chloride ion penetration, freeze-thaw cycle, carbonation, and sulfate resistance of concrete mixed with CG/CGS, and comprehensively discusses the influence of CG/CGS on the durability of concrete. It is expected to provide the research foundation and theoretical support

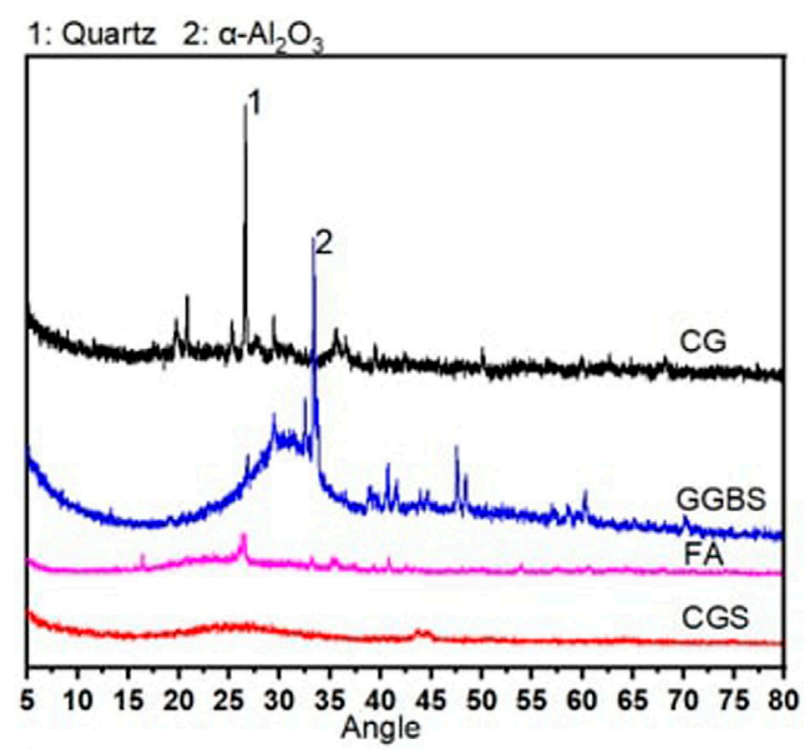

FIGURE 2 | XRD spectra of CG, CGS, GGBS and FA.

for CG/CGS as SCM. However, this study only analyzed the concrete with the replacement rate of SCMs of $30 \%$, and the test work of other additives needs to be carried out further. 


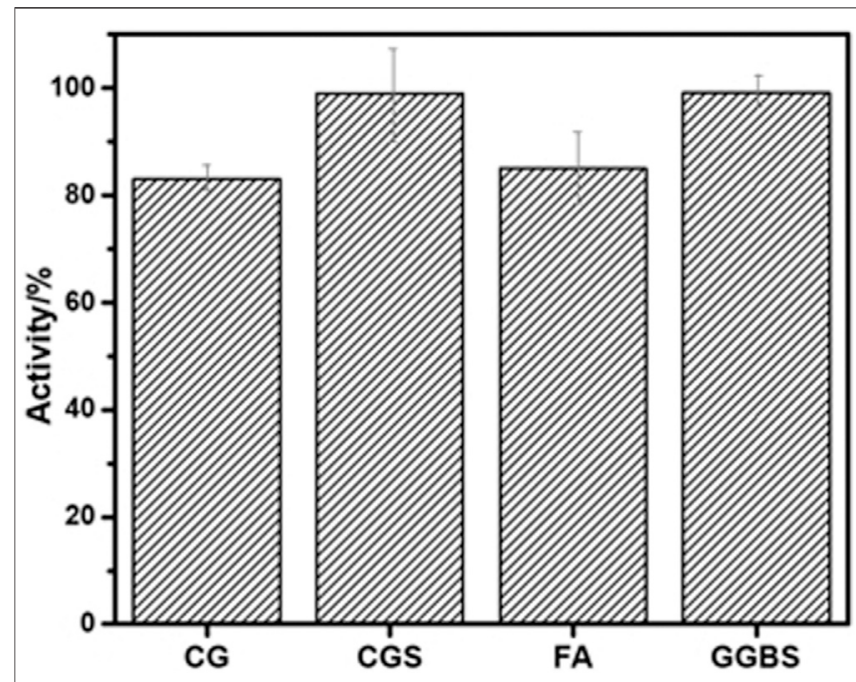

FIGURE 3 | Activity of raw materials.

\section{MATERIALS AND METHODS}

\section{Materials}

Following four types of supplementary cementitious materials and ordinary Portland cement were selected in this study: 1) Lowcalcium CG: calcined at $800^{\circ} \mathrm{C}$; 2) CGS: grinded for $50 \mathrm{~min}$ and sieved to a particle size below 200 mesh size; 3) FA: from Yibin City, Sichuan Province; 4) GGBS: obtained from Chongqing municipality; 5) C: Ordinary Portland cement, CEM I 42.5. The morphology was determined using a scanning electron microscope (SEM), as illustrated in Figure 1. CGS particles have several shapes such as platy and prismatic, and most of them were agglomerated with the dense smooth surface with few pores on the exterior surface. The structure of CG turns to irregular and porous at $800^{\circ} \mathrm{C}$ heating temperature, which may be caused by the dehydroxylation of kaolinite and phase change to metakaolin. The XRD spectra of CG, CGS, GGBS, and FA are shown in Figure 2. There are obvious characteristic peaks of crystalline $\mathrm{SiO}_{2}$ in CG. GGBS and FA contain a small amount of crystalline $\mathrm{SiO}_{2}$. There is no obvious characteristic peak of crystalline phase in CGS, indicating that most of them are amorphous phase. GGBS contains more alumina phase.

The chemical composition results and the activity of the cementitious materials were determined (Figure 3; Table 1). It can be seen from the table that CG and CGS have similar contents of $\mathrm{SiO}_{2}$ and $\mathrm{Al}_{2} \mathrm{O}_{3}$, which are lower than $\mathrm{FA}$ and higher than
GGBS. CGS has a higher content of $\mathrm{CaO}$ than CG, which indicates that the hydraulic activity of cementitious materials is influenced by its chemical composition.

\section{Preparation of Samples}

Concrete specimens were cast at a water to cement ratio of 0.37 . Aggregates smaller than $4.75 \mathrm{~mm}$ and up to $0.075 \mathrm{~mm}$ are considered fine aggregate. The total amount of cementing material was $450 \mathrm{~kg}$, and the other samples except $\mathrm{C}$ were replaced by CG, CGS, and FA at the contents of $30 \%$ by the mass of cement, respectively. Coarse aggregate, cementite, fine aggregate, and water were added in a standard mixer after all the ingredients were prepared, and blend for 2 min until smooth. After that, the performance of concrete mixture was inspected according to the Chinese standard GBT50080-2016. Table 2 lists the different SCMs used in the concrete mixes that influence the workability of concrete. The effect of FA, GGBS, and CGS enhanced the slump; on the other hand, CG shows a reduction in workability compared to the C. The reason is that CG particles are porous and loose, which will absorb part of the water and affect fluidity.

\section{METHODS}

\section{Mechanical Properties}

The compressive strength testing of the samples has been started at the age of 28 days. Concrete cubes $100 \mathrm{~mm} \times 100 \mathrm{~mm} \times$ $100 \mathrm{~mm}$ in size were cast according to Chinese standard GB/T 50,081 . The loading rate is $3 \mathrm{kN} / \mathrm{s}$, and the average value of three samples was used for the determination of compressive strength values. The compressive strength was calculated by following formula.

$$
f_{c c}=\frac{F}{A} \times \lambda
$$

$f_{c c}$ : compressive strength of concrete cube sample, $\mathrm{MPa}$;

$F$ : sample failure loads, $\mathrm{kN} / \mathrm{s}$;

$A$ : sample bearing pressure area, $\mathrm{mm}$;

$\lambda$ : dimensional conversion factor, herein is 0.95 .

\section{Pore Structure Parameters}

In this paper, mercury intrusion porosimetry is used to determine the pore structure parameters of concrete. For the sample preparation, core-drilling is the core sampling method that was adopted for the consideration of protecting the original pore structure of samples. After that, the samples were dried in a 50 -degree vacuum oven for $48 \mathrm{~h}$ to remove free water before

TABLE 1 | Chemical composition of cement CG, CGS, FA, and GGBS (wt\%).

\begin{tabular}{|c|c|c|c|c|c|c|c|c|c|c|c|c|c|}
\hline & $\mathrm{SiO}_{2}$ & $\mathrm{Al}_{2} \mathrm{O}_{3}$ & $\mathrm{CaO}$ & $\mathrm{Fe}_{2} \mathrm{O}_{3}$ & K2O & MgO & TiO2 & $\mathrm{Na2O}$ & MnO & $\mathrm{SO}_{3}$ & C & f-CaO & LOI \\
\hline Cement & 21.39 & 5.15 & 61.04 & 3.86 & 0.62 & 2.82 & 0.85 & 0.64 & - & 3.10 & - & - & - \\
\hline CG & 4.12 & 23.98 & 6.36 & 14.76 & 1.48 & 1.48 & 4.26 & 1.09 & 0.19 & 1.71 & - & - & 1.1 \\
\hline CGS & 45.44 & 26.37 & 12.30 & 9.29 & 1.28 & 1.11 & 1.04 & 0.91 & 0.37 & 0.17 & 1.08 & 2.8 & 0.7 \\
\hline FA & 0.39 & 27.49 & 4.47 & 8.47 & 2.03 & 0.95 & 2.92 & 0.1 .41 & - & 1.16 & - & - & 1.5 \\
\hline GGBS & 34.64 & 13.96 & 33.10 & 2.51 & 0.79 & 5.68 & 6.14 & 1.42 & - & - & - & - & 0.8 \\
\hline
\end{tabular}


TABLE 2 | Proportion of concrete samples $\left(\mathrm{kg} / \mathrm{m}^{3}\right)$.

\begin{tabular}{|c|c|c|c|c|c|c|c|c|c|c|}
\hline Sample & $W / c$ & Cement/kg & $\mathrm{FA} / \mathbf{k g}$ & GGBS/kg & CG/kg & CGS/kg & Sand/kg & Gravel/kg & Slump/kg & Air content $/ \%$ \\
\hline C & 0.37 & 450 & - & - & - & - & 795 & 1,000 & 12.0 & 1.25 \\
\hline FA & 0.37 & 315 & 135 & - & - & - & 795 & 1,000 & 22.0 & 1.50 \\
\hline GGBS & 0.37 & 315 & - & 135 & - & - & 795 & 1,000 & 24.0 & 1.25 \\
\hline CG & 0.37 & 315 & - & - & 135 & - & 795 & 1,000 & 11.5 & 1.20 \\
\hline CGS & 0.37 & 315 & - & - & - & 135 & 795 & 1,000 & 21.0 & 0.95 \\
\hline
\end{tabular}

the test. The instrument uses the American PM60GT-18 mercury porosimeter, in which the maximum pressure of the instrument is $325 \mathrm{Mpa}$, and the range of pore size is $3 \mathrm{~nm}$ to $950 \mu \mathrm{m}$. The porosity tests were made on the evenly corroded cement paste samples of $2 \mathrm{~mm}$ thick, which ensured the reproducibility of the measurements.

\section{Chloride Penetration Resistance}

The tests for chloride ion penetration were in accordance with Chinese standard GB/T 50,082.

The method of electric flux was as follows: 1) Cylinder specimens with diameter of $(100 \pm 1) \mathrm{mm}$ and height of $(50 \pm$ 2) $\mathrm{mm}$ were cured for 28 days; 2) Silica gel or resin sealing material was applied to brush the cylinder side of the specimen, and the specimen was vacuum-saturated; 3) $0.3 \mathrm{~mol} / \mathrm{L} \mathrm{NaOH}$ solution and $3 \% \mathrm{NaCl}$ solution were placed in the testing cells on two sides of the sample, respectively, and connected to the power supply; 4) the DC power was switched on $60 \pm 0.1 \mathrm{~V}$, record the results each $30 \mathrm{~min}$.

\section{Freezing and Thawing Resistance}

After curing for 24 days, the prismatic specimens of $100 \mathrm{~mm} \times$ $100 \mathrm{~mm} \times 400 \mathrm{~mm}$ were toked out and immersed in water with a temperature of $(20 \pm 2)^{\circ} \mathrm{C}$ for 4 days, and the initial value of fundamental frequency and weight of the specimens was measured. Then, put the specimens into the freeze-thaw testing machine. Each cycle of freezing and thawing was completed within $2-4 \mathrm{~h}$; the transverse fundamental frequency and the quality of the specimen should be measured every 25 freeze-thaw cycles.

\section{Sulfate Attack Resistance}

For sulfate attack resistance test, concrete specimens of $100 \mathrm{~mm} \times$ $100 \mathrm{~mm} \times 100 \mathrm{~mm}$ cube were prepared. The test as following procedure: 1) specimens were initially placed in an oven to be dried at $(80 \pm 5)^{\circ} \mathrm{C}$ for $48 \mathrm{~h}$ and cool down to room temperature; 2$)$ immersed the specimens in $5 \%$ sodium sulfate solution. The solution was replaced each month. One cycle included $15 \mathrm{~h}$ of soaking time and $5.5 \mathrm{~h}$ of drying time which was maintaining at the temperature of $80 \pm 5^{\circ} \mathrm{C}$, then cooling after drying. Each cycle lasted for about $(24 \pm 2) \mathrm{h}$. Also, it is worth noting that according to GB/T 50,082 standard, the test can be stopped when the corrosion resistance coefficient of compressive strength reaches $75 \%$.

\section{Carbonation Resistance}

Prism specimens were cast and left in the cast area and demolded $24 \mathrm{~h}$ after casting. After demolding, the specimens were cured in standard curing room for 26 days. Subsequently, take out the test piece and bake it at $60^{\circ}$ for $48 \mathrm{~h}$. The specimens were moved to a carbonization chamber with carbon dioxide concentration, relative humidity and temperature of $(20 \pm 3) \%(70 \pm 5) \%$ and $(20 \pm 2) \%$, respectively, for carbonization test. On days 3 , 7,14 , and 28 , split the samples and spray $1 \%$ phenolphthalein ethanol solution (the ethanol solution contains $20 \%$ distilled water) to measure the carbonization depth.

\section{RESULTS}

\section{Mechanical Properties}

The compressive strength and strength ratio of CG-, CGS-, FA-, and GGBS-added concrete is shown in Figure 4. It could be known that the strength of all samples was increased with a curing time increase of 3-56 days. C samples showed the highest strength as $100 \%$ cement was used.

Both CG and CGS samples suggested that the strength development trend is better than FA and GGBS. The strength is higher than that of $\mathrm{C} 45$ concrete after 28 days of curing, which fully meets the construction requirements. CG samples showed peak strength when compared with CGS-, FA-, and GGBS-added samples before 14 days curing time. It indicated that CG has higher activity at the early age compared with CGS, FA, and GGBS. The highest strength about $63 \mathrm{MPa}$ was shown by CG sample when curing age up to 56 days. CGS-added concrete revealed higher strength than FA-added samples. Strength of concrete with CG, CGS, FA, and GGBS-added (CG, CGS, GGBS, FA for short) was inconsistent with the activity results of CG, CGS, FA, and GGBS. It may be related to the powder fineness and the accumulation state in the concrete system (Martin et al., 2006; Berodier and Scrivener, 2014; Zunino and Lopez, 2016; Hemalatha and Santhanam, 2018).

\section{Porosity and Pore Diameter}

It has been well accepted that the addition of supplementary materials modifies the microstructure of cement paste. The total porosity of cement-based materials with SCMs can be affected by chemical (pozzolanic reaction) and physical (compactness) influences (Cyr, 2013). The structure of cement mortar is complex, and the size of the internal pores has a large span. Bout et al. roughly divide the pore size into four categories and give the impact of each level of pores on the performance: the gel pore, with pore size of less than $20 \mathrm{~nm}$ (harmless pore); the transition pore, with diameter in the range of $10-100 \mathrm{~nm}$ (less harmful pores); the capillary pore, with diameter in the range of 

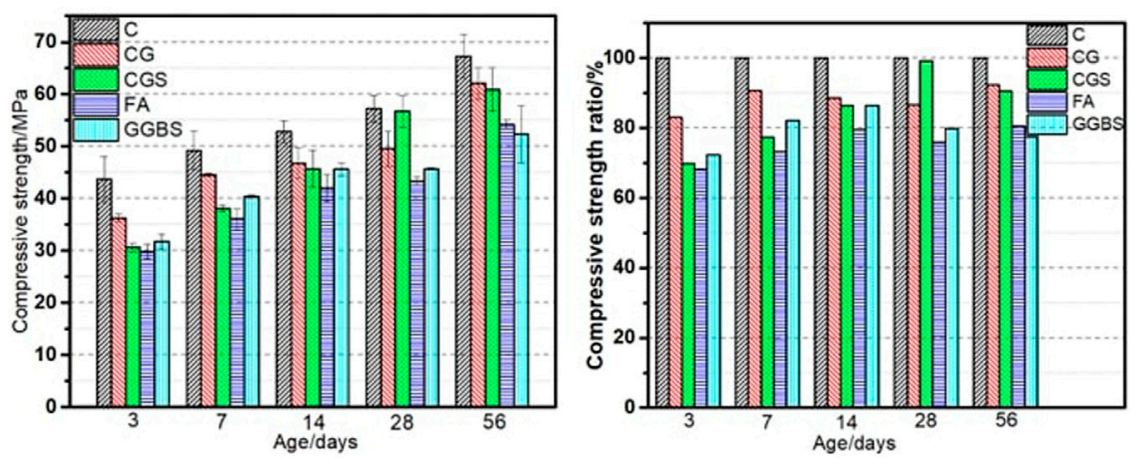

FIGURE 4 | Compressive strength and compressive strength ratio of concrete samples.

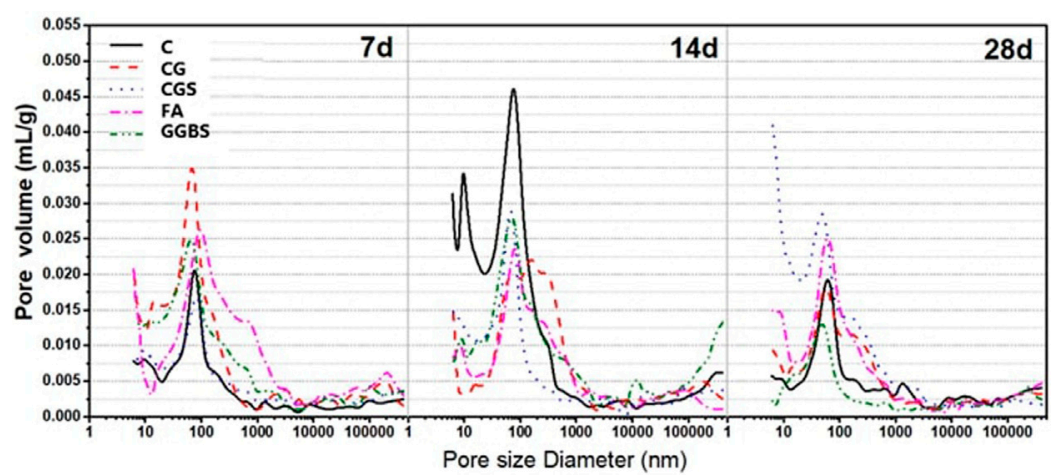

FIGURE 5 | Pore size distribution of concrete samples.

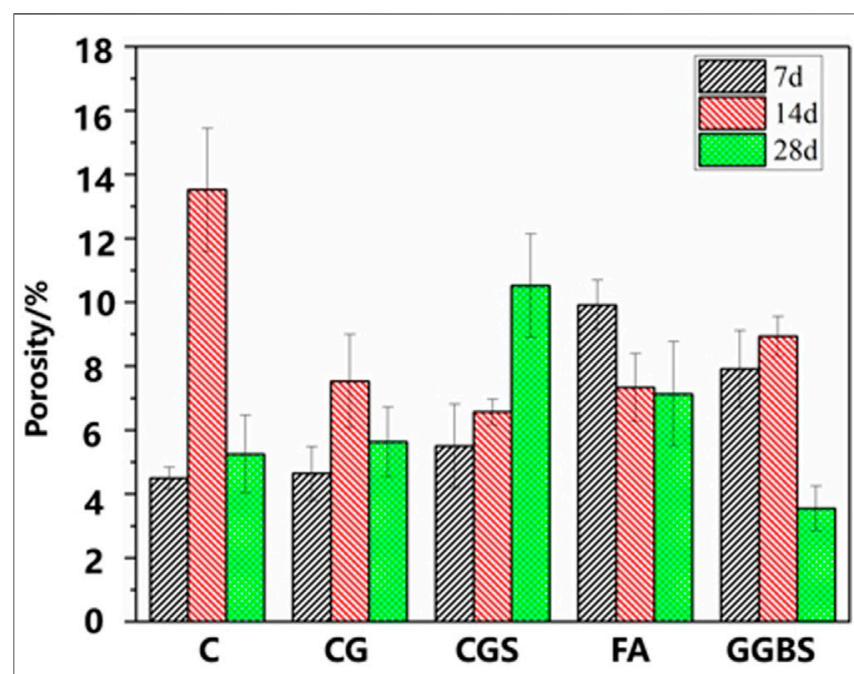

FIGURE 6 | Porosity of concrete samples.

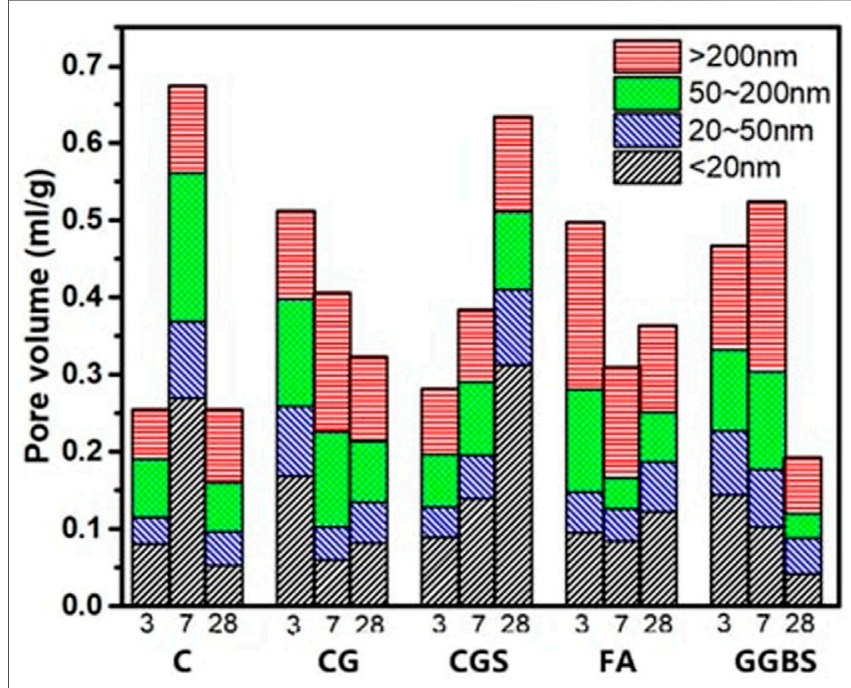

FIGURE 7 | Pore volume of concrete samples. 


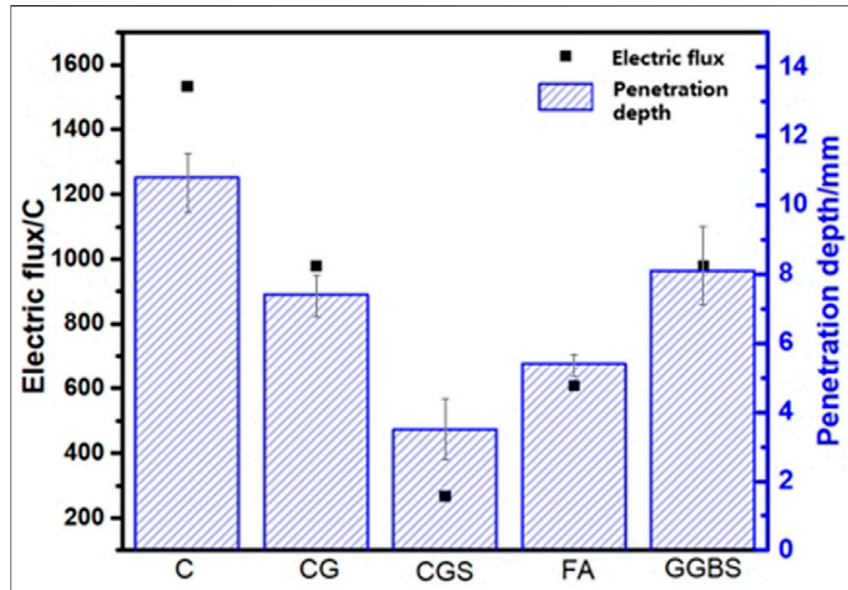

FIGURE 8 | Chloride resistance of concrete.

$100-1000 \mathrm{~nm}$ (harmful pores); and the macro pores, with pore size of greater than $1000 \mathrm{~nm}$ (Long et al., 2017). Figures 5-7 exhibit the pore structure of concrete at different ages. The concrete addition of SCMs has larger porosity, and the size of pores owing to a smaller quantity of hydrates is formed in the paste at the early age. At this time, the pozzolanic reaction has hardly occurred to produce calcium silicate hydrate, and the concrete mixed with SCMs will generally last for several days (when the amount of SCMs is added, the time may be prolonged; however, when the activity of SCMs is high, the time may be shortened, depending on the situation).

It can be found that the samples cured for 7 days with CG illustrated more pores, which is because the SCMs have lower activity at the early age and the structure is relatively loose at the early of hydration; Wang et al. published the same results (Wang et al., 2012). All specimens except CGS (it should be noted that the porosity of CGS concrete increases significantly with the hydration process, considering that the test operation may cause errors in the results; however, the reasons for this phenomenon need further study) showed the same trend that the hydration products $\mathrm{C}-\mathrm{S}-\mathrm{H}$ gel filled the pores and reduced the porosity with the hydration proceeding after curing for 14 days. The $5.63 \%$ porosity of CG is similar to C (5.25\%), and less than FA (7.13\%) at the curing age of 28 days.

\section{Chloride Penetration Resistance}

Mineral admixtures can effectively improve the internal pore structure and interface area of concrete, and to a large extent hinder the chloride ion erosion of concrete, which is one of the effective measures to improve the chloride ion erosion resistance of concrete. The reasons that mineral admixtures is able to improve the resistance of concrete to chloride ion erosion mainly include the following two aspects: first, the addition of mineral admixtures can effectively optimize the internal microstructure of concrete, thus improving its diffusion resistance to chloride ion infiltration; second, the secondary hydration reaction of cement after the addition of

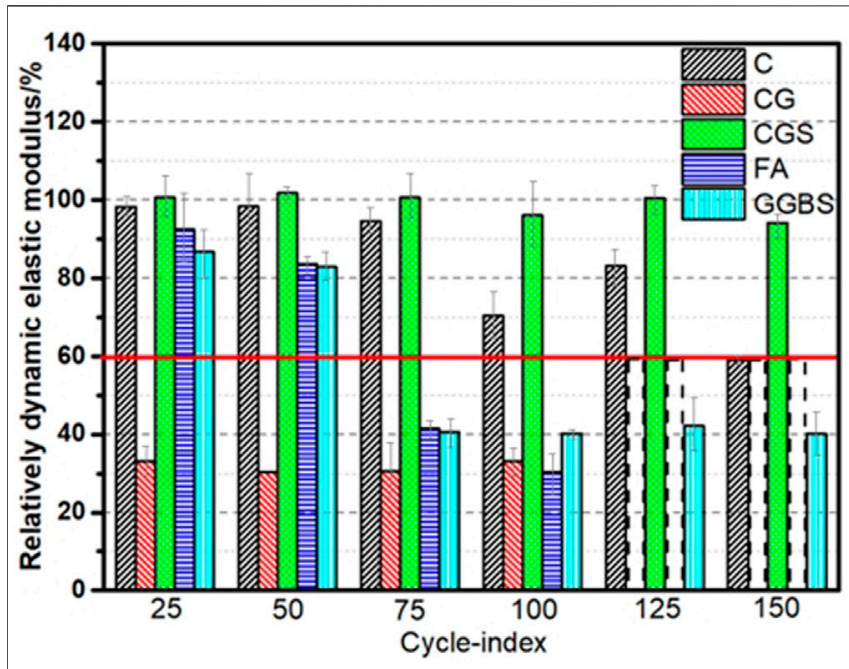

FIGURE 9 | Relatively dynamic elastic modulus of concrete under different freezing and thawing cycles.

mineral admixtures generates low-alkaline C-S-H gel, which can enhance the chemical binding ability and physical adsorption ability of concrete to chloride ions. The following contents will summarize and analyze the influence of various mineral admixtures on the chloride ion resistance of concrete.

The results of electric flux and penetration depth of concrete are summarized in Figure 8. It can be obviously seen that the electric flux of $\mathrm{C}$ is larger than CGS and CG, which indicates that CGS and CG significantly reduced the electric flux of concrete. CGS has the best effect, and CG is similar to FA.

The penetration depth of chloride ions is consistent with the electrical flux. The penetration depth of chloride ions in the $\mathrm{C}$ was the largest at $10.8 \mathrm{~mm}$, and the smallest of CGS at $1.8 \mathrm{~mm}$. The CG was lower than GGBS at $7.8 \mathrm{~mm}$. Such a phenomenon perhaps due to high amounts of alumina contents exhibited a much better resistance to chloride ion penetration (Mucteba et al., 2012).

\section{Freeze-Thaw Resistance}

At present, the evaluation indexes of concrete freeze-thaw damage include relative dynamic elastic modulus change, mass loss rate, compressive strength loss rate, and damage layer thickness. The relative dynamic elastic modulus change is used as the evaluation index in this study.

Figure 9 shows that the relative dynamic elasticity modulus of CG is always lower than other concrete, which is less than $35 \%$ after 25 th freeze-thaw cycle. According to the GB/T50082 standard, it is stipulated that the test needs to be stopped when the freeze-thaw cycle has reached the specified number of times, the relative dynamic elastic modulus has dropped to $60 \%$ $(\leq 60 \%)$, or the mass loss rate has reached $5 \%$. The relative dynamic elastic modulus of the CG has been low as $30.3 \%$, indicating that it has been destroyed, which proved the CG has little resistance to freeze-thaw damage. The reason why the CG 
A

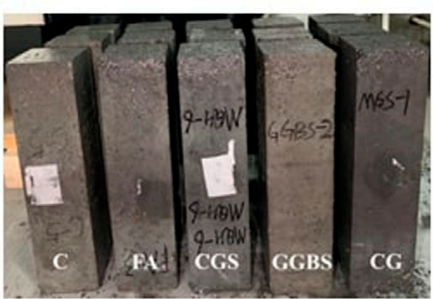

Concrete samples after 25 freeze-thaw cycles

B

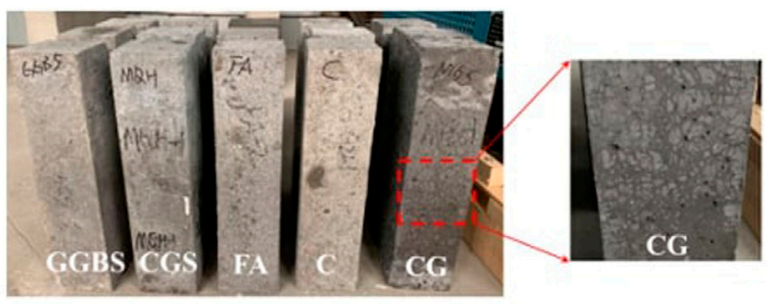

Concrete samples after 50 freeze-thaw cycles

C
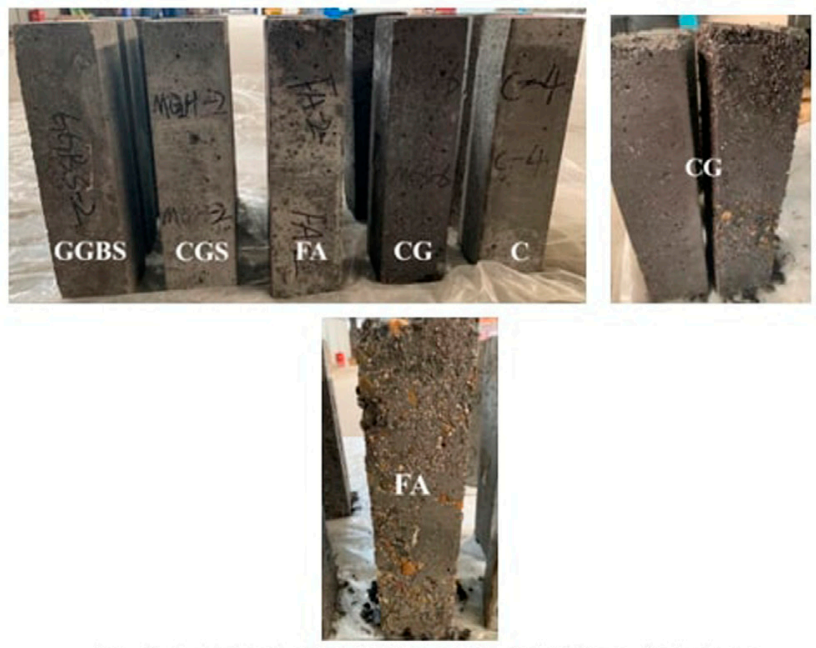

Visual appearance of deteriorated prisms after 75 freeze-thaw cycles

FIGURE 10 | Freezing and thawing resistance of concrete (A) Concrete samples after 25 freeze-thaw cycles (B) Concrete samples after 50 freeze-thaw cycles (C) Visual appearance of deteriorated prisms after 75 freeze-thaw cycles.

specimens were first frozen and damaged may also be due to the good water absorption of the CG after calcination (Wang et al., 2021; Zhang et al.,. 2021), and the previous slump results also confirmed this view. The external water is more likely to enter the interior of the concrete. After freezing at low temperature, frost heave pressure will be generated, which will promote the development of cracks. Accelerate the frost heave and fall off of the outer layer of the specimen. The freeze-thaw resistance grade of the FA and GGBS is F50. With the freeze-thaw cycle reaching 150 times, no obvious damage was found in the concrete mixed with CGS. It illustrates that the CGS has excellent resistance to freeze-thaw damage.

The apparent quality of the freeze-thaw cycle of concrete is shown in Figure 10. When the freeze-thaw cycle reaches 25 cycles, no distinct cracks appeared. As the freeze-thaw cycle reaches 50 cycles, micro-cracks appear on the surface of CG; meanwhile, the internal freeze-thaw water flows out through the cracks, which indicates that its internal structure has been significantly damaged. The other samples showed no obvious damage except for the upper and lower surfaces. When 75 cycles of freezing and thawing were done, a large amount of aggregate fell off and broken during the sampling process of one of the CG specimens; similarly, the FA and GGBS specimens also appeared evident damage.

\section{Sulfate Attack Resistance}

There are two main reasons for the influence of $\mathrm{Na}_{2} \mathrm{SO}_{4}$ solution on the quality of concrete under the combined action of dry and 


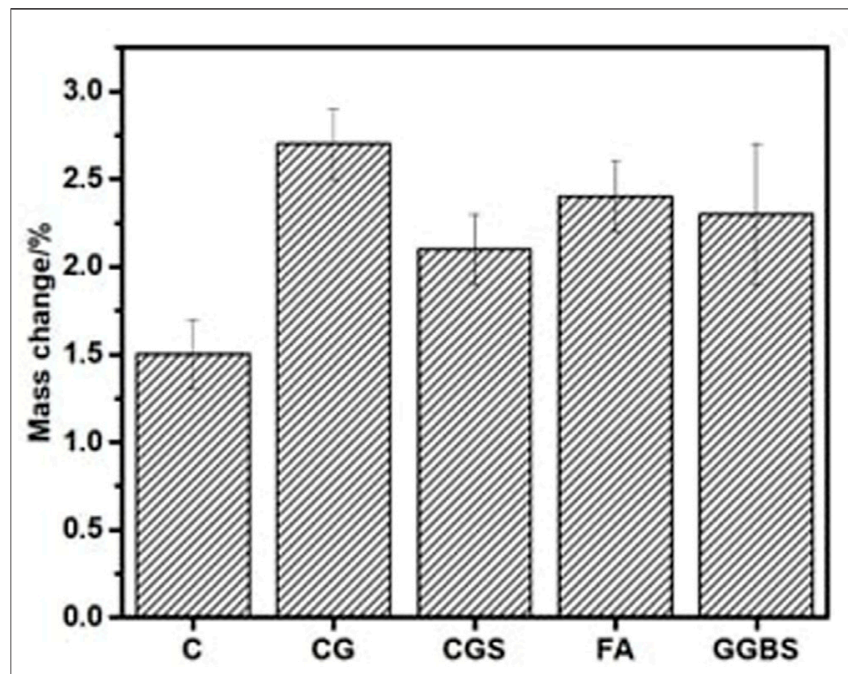

FIGURE 11 | Mass change ratio of concrete.

wet cycles: on the one hand, the $\mathrm{SO}_{4}{ }^{2-}$ that enter the concrete reacted with the hydration products and generated the erosion products which fill and accumulate in the pores of the concrete, temporarily increasing the quality of concrete; on the other hand, the corrosion products are expansive. Under the combined action of dry and wet cycles, the expansion stress will cause the concrete to crack and peel, reducing the quality.

The mass change ratio and the compressive strength ratio of all specimens after 30 cycles of immersion were recorded and illustrated in Figures 11, 12. It can be found that each specimen presented a decline in mass. Compared with ordinary concrete, concrete mixed with SCMs shows weak resistance to sulfate erosion. The reason is that there are many hydration products that can participate in chemical reactions in ordinary concrete, and the amount of corrosion products generated is large, which improves the compactness. However, the degradation of CG mass $(-2.7 \%)$ is the most obvious among all the specimens. Meanwhile, the compressive strength ratio (41.5\%) of CG is also the highest loss (Figure 12). Not only CG, but also CGS showed a similar trend. Therefore, in certain sense, the change ratio of mass also reflects the change ratio of compressive strength. The aluminum element contained in CG and CGS causes the $\mathrm{C}_{3} \mathrm{~S}$ hydration to generate ettringite which is an erosion product under sulfate erosion, and it will intensify the damage of sulfate erosion (Wang et al., 2018). The reason for this phenomenon may be due to the fact that the aluminum phase in CG combines with other elements to form another compound. Therefore, $\mathrm{Al}_{2} \mathrm{O}_{3}$ was not founded in CG.

\section{Carbonation Resistance}

Figure 13 shows the carbonation depth of the samples using CG and CGS after 28 days of the accelerated carbonation test. A carbonation phenomenon of all the samples was not observed at the first 3 days, and the carbonation depth increases gradually with an increase in exposure time. It is not difficult to see that $\mathrm{C}$ showed a lower carbonation depth

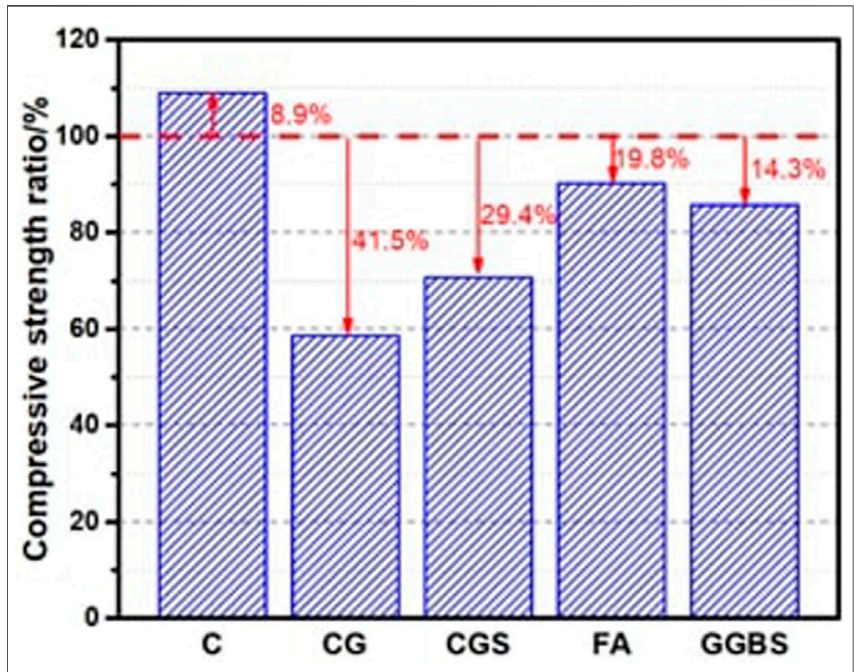

FIGURE 12 | Compressive strength ratio of concrete under $10 \mathrm{wt} . \%$ $\mathrm{Na}_{2} \mathrm{SO}_{4}$ solution (wetting-drying) 30 days.

than other groups at 28 days of curing, about $5 \mathrm{~mm}$, and the carbonization depth of concrete mixed with CG was the largest, about $7.9 \mathrm{~mm}$, followed by CGS, about $7.6 \mathrm{~mm}$.

Although many researchers have done comparative experiments on concrete carbonization with and without SCMs, generalizations remain difficult. The overall trend found in the literature is that the depth of carbonation increases with the use of pozzolan in concretes (Shi et al., 2009). The author considers that there are two reasons that lead to this carbonization experiment results: the first one, the pozzolanic reaction consumes $\mathrm{Ca}(\mathrm{OH})_{2}$, which implies that a smaller amount of $\mathrm{CO}_{2}$ is required to carbonate the remaining hydrates; when the amount of $\mathrm{Ca}(\mathrm{OH})_{2}$ present is lower, the carbonization depth is larger. This view is consistent with the conclusion drawn by (Bier, 1986). The second one, a large SCM content weakens the accumulation effect of SCM particle, and the increases of the capillary pore content of the specimen will accelerate the carbonization depth. Although concretes containing SCMs are sometimes considered as less resistant to carbonation (especially in accelerated tests) due to their low portlandite content, this property should not be considered alone regarding the risk of corrosion since the SCMs can sometimes reduce the permeability of the concrete (Bouikni et al., 2009). Moreover, it has been shown that many concrete with SCMs have very low probabilities of corrosion after several tenths of years (due to lower permeability), meaning that in the whole life cycle of concrete, the influence of carbonization effect at the early stage is insignificant (Ciaran and Emma, 2012).

\section{DISCUSSION}

From the observed relationship between SCM activity and 28 days compressive strength, it can be seen that activity is positively correlated with compressive strength. The higher the 


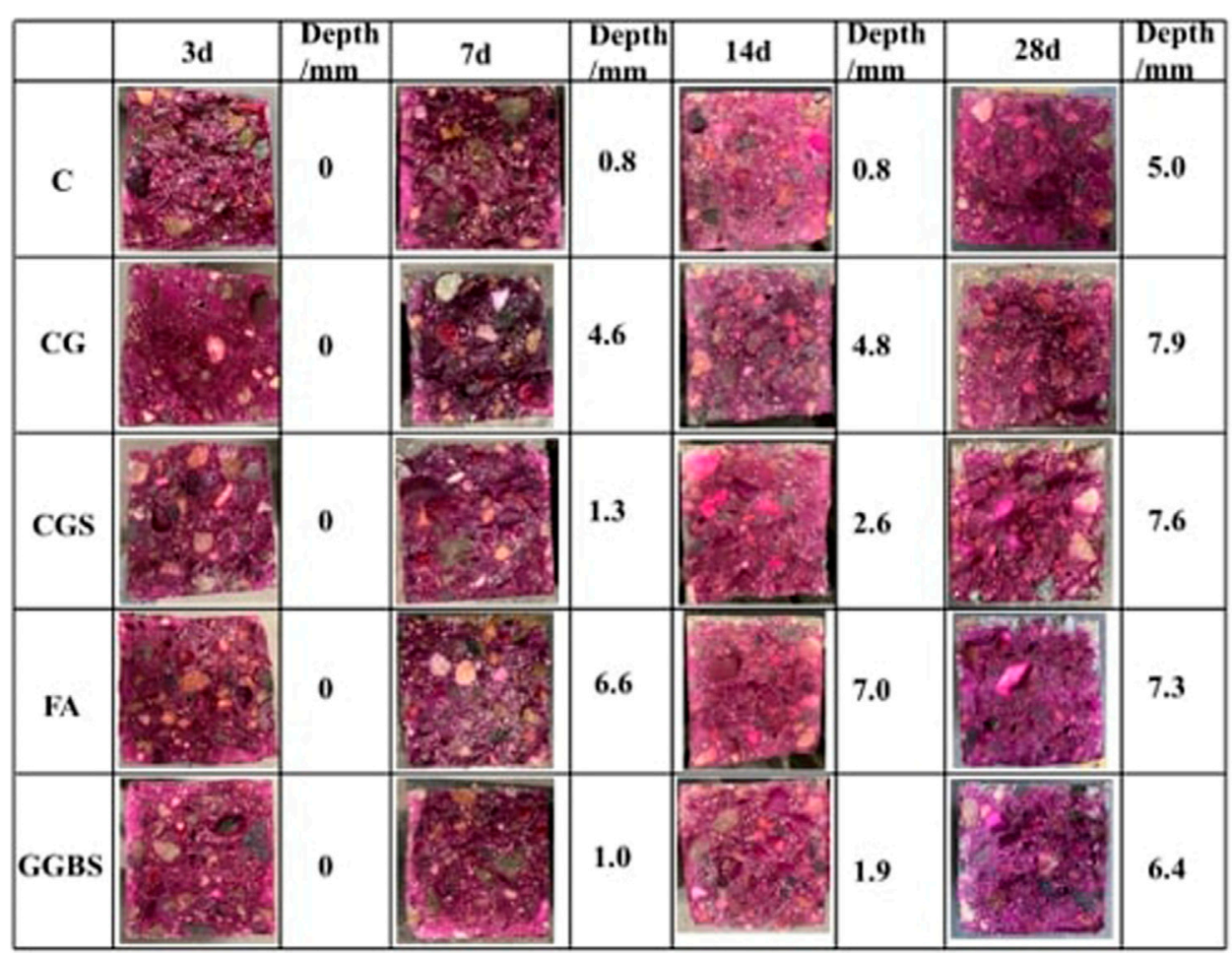

FIGURE 13 | Carbonation depth and visual appearance of concrete with different time.

activity, the greater the compressive strength. From the results of concrete electric flux, it can be seen that the permeability resistance performance of CG and CGS is better than that of C. In addition, a comparative analysis of porosity and electric flux results shows that CG has lower porosity but poorer permeability, which may be due to better connectivity of pore structure. The better the pore connectivity, the easier it is for external material to enter the concrete and reduce durability. However, CGS has high porosity but poor interconnectivity, resulting in strong impermeability and good durability. Therefore, we consider that there is no strong correlation between concrete durability and porosity. Moreover, the pore distribution results show that CGS concrete has a large porosity and is easier to form gel pores during the hydration process, but considering the reason of insufficient sample quantity in this study, there may be errors in the results, and future investigations are necessary to validate the kinds of conclusions. Besides, since this study only discussed the concrete performance of CG and CGS with 30\% content, the durability of concrete with 40 and 50\% content of CG and CGS will be studied (Osborne believes that when $60 \%$ gasification slag is used instead of Portland cement to produce concrete, the resistance to sulfate attack and chloride invasion is not obvious (Osborne, 1994); therefore, the future work mainly studies the durability of concrete with CG and CGS content less than $60 \%$ ), and the influence of the content on its durability will be analyzed in the future work.

\section{CONCLUSION}

Overall, CG and CGS can affect the durability of concrete. The chief conclusions of this study can be drawn as follows:

1) The strength of the concrete with CG and CGS added after curing for 56 days can reach more than $60 \mathrm{Mpa}$, indicating that CG and CGS concrete can satisfy the requirements of ordinary construction under reasonable processing technology.

2) Both CG-added and CGS-added concrete illustrated great chloride penetration resistance. If it is used in a chloride salt environment, it shows a strong advantage by adding CGS.

3) CG and CGS concrete have weak sulfate attack resistance compared to ordinary Portland cement. The aluminum element contained in CG and CGS will intensify the damage of sulfate erosion.

4) CGS-added concrete has great capacity in the freeze-thaw resistance. On the contrary, CG has little resistance to freezethaw damage.

5) The results for the use of CG and CGS revealed that the two SCMs could not effectively contribute to a better performance in carbonation resistance.

\section{DATA AVAILABILITY STATEMENT}

The raw data supporting the conclusions of this article will be made available by the authors, without undue reservation. 


\section{AUTHOR CONTRIBUTIONS}

XZ from China Western Construction Academy of Building Materials Co., Ltd. was responsible for the experimental design. ZG from Southeast University was in charge of the experiment. WY from China West Construction Group Co., Ltd. was in charge of the analysis experiment. WS from China Western Construction Academy of Building Materials Co., Ltd. was responsible for data collation.

\section{REFERENCES}

Berodier, E., and Scrivener, K. (2014). Understanding the Filler Effect on the Nucleation and Growth of C-S-H. J. Am. Ceram. Soc. 97 (12), 3764-3773. doi:10.1111/jace.13177

Bier, T. A. (1986). Influence of Type of Cement and Curing on Carbonation Progress and Pore Structure of Hydrated Cement Pastes. MRS Proc. 85, 123. doi:10.1557/PROC-85-123

Borosnyói, A. (2016). Long Term Durability Performance and Mechanical Properties of High Performance Concretes with Combined Use of Supplementary Cementing Materials. Construction Building Mater. 112, 307-324. doi:10.1016/j.conbuildmat.2016.02.224

Bouikni, A., Swamy, R. N., and Bali, A. (2009). Durability Properties of concrete Containing 50\% and 65\% Slag. Construction Building Mater. 23 (8), 2836-2845. ISSN 0950-0618. doi:10.1016/j.conbuildmat.2009.02.040

Ciaran, M., and Emma, S. (2012). Probability-Based Assessment of the Durability Characteristics of Concretes Manufactured Using CEM II and GGBS Binders. Construction Building Mater. 30, 22-29. doi:10.1016/j.conbuildmat.2011.11.029

Cyr, M. (2013). Influence of Supplementary Cementitious Materials (SCMs) on concrete Durability. Eco-Efficient Concrete, 153-197. doi:10.1533/9780857098993.2.153

Hemalatha, M. S., and Santhanam, M. (2018). Characterizing Supplementary Cementing Materials in Blended Mortars. Construction Building Mater. 191, 440-459. doi:10.1016/j.conbuildmat.2018.09.208

Kaur, G., Singh, S. P., and Kaushik, S. K. (2012). Reviewing Some Properties of concrete Containing mineral Admixtures. Indian Concrete J. 86, 7.

Lollini, F., Redaelli, E., and Bertolini, L. (2016). A Study on the Applicability of the Efficiency Factor of Supplementary Cementitious Materials to Durability Properties. Construction Building Mater. 120, 284-292. doi:10.1016/j.conbuildmat.2016.05.031

Long, W., Xiao, B., Zhou, B., and Liang, P. (2017). Research on the Internal Pores in Alkali-Activated Slag Cementing Material via X-CT Three-Dimensional Imaging Microscopy. AIP Conf. Proc. 1794 (1), 020001. doi:10.1063/1.4971883

Luo, F., Jiang, Y., and Wei, C. (2021). Potential of Decarbonized Coal Gasification Residues as the mineral Admixture of Cement-Based Material. Construction Building Mater. 269, 121259. doi:10.1016/j.conbuildmat.2020.121259

Martin, C., Philippe, L., and Erick, R. (2006). Efficiency of Mineral Admixtures in Mortars: Quantification of the Physical and Chemical Effects of Fine Admixtures in Relation with Compressive Strength. Cement Concrete Res. 36 (2), 264-277. doi:10.1016/j.cemconres.2005.07.001

Mucteba, U., Kemalettin, Y., and Metin, I. (2012). The Effect of mineral Admixtures on Mechanical Properties, Chloride Ion Permeability and Impermeability of Self-Compacting concrete. Construction Building Mater. 27 (1), 263-270. doi:10.1016/j.conbuildmat.2011.07.049

National Precast Concrete Association (2010). Using Fly Ash in Concrete. Available at: https://precast.org/2010/05/using-fly-ash-in-concrete/ (Accessed September 26, 2021).

Osborne, G. (1994). The Durability of Gasifier Slag and Fly Ash Cement Concretes in Aggressive Environments. South Africa.

Pomykała, R. (2014). The Mechanical Properties of Coal Gasification Slag as a Component of Concrete and Binding Mixtures. Polish J. Environ. Stud. 23 (4), 1403-1406.

Purebase (2021). About SCM. Available at: https://purebase.com/supplementarycementitious-materials/ (Accessed September 6, 2021).

Qi, B., Gao, J., Chen, F., and Shen, D. (2017). Evaluation of the Damage Process of Recycled Aggregate Concrete under Sulfate Attack and Wetting-Drying Cycles.

\section{FUNDING}

This work was supported by National key research and development plan for key projects of solid waste recycling (2019YFC1907200), Sichuan Science and Technology Program (2021YJ0530), and Major science and technology project of Jiangxi Provincial Department of water resources (202124zdkt28).

Construction Building Mater. 138, 254-262. doi:10.1016/ j.conbuildmat.2017.02.022

Rahla, K. M., Mateus, R., and Bragança, L. (2019). Comparative Sustainability Assessment of Binary Blended Concretes Using Supplementary Cementitious Materials (SCMs) and Ordinary Portland Cement (OPC). J. Clean. Prod. 220, 445-459. doi:10.1016/j.jclepro.2019.02.010

Shi, H.-S., Xu, B.-W., and Zhou, X.-C. (2009). Influence of Mineral Admixtures on Compressive Strength, Gas Permeability and Carbonation of High Performance Concrete. Construction Building Mater. 23 (5), 1980-1985. doi:10.1016/ j.conbuildmat.2008.08.021

Wang, A., Liu, P., Mo, L., Liu, K., Ma, R., Guan, Y., et al. (2021). Mechanism of thermal Activation on Granular Coal Gangue and its Impact on the Performance of Cement Mortars. J. Building Eng. [Preprint] Available at: https://www.sciencedirect.com/ science/article/abs/pii/S2352710221014741 (Accessed November 13, 2021).

Wang, Q., Yan, P., and Mi, G. (2012). Effect of Blended Steel Slag-GBFS mineral Admixture on Hydration and Strength of Cement. Construction Building Mater. 35, 8-14. doi:10.1016/j.conbuildmat.2012.02.085

Wang, Y., He, X., Su, Y., Ma, B., Chu, J., and Jiang, B. (2018). Effect of Aluminium Phases on Thaumasite Formation in Cement Slurries Containing limestone Powder. Mag. Concrete Res. 70 (12), 610-616. doi:10.1680/jmacr.16.00521

Wang, Y., Tan, Y., Wang, Y., and Liu, C. (2020). Mechanical Properties and Chloride Permeability of Green Concrete Mixed with Fly Ash and Coal Gangue. Construction Building Mater. 233, 117166. doi:10.1016/j.conbuildmat.2019.117166

Zhang, J., Chen, T., and Gao, X. (2021). Incorporation of Self-Ignited Coal Gangue in Steam Cured Precast concrete. J. Clean. Prod. 292, 126004. doi:10.1016/ j.jclepro.2021.126004

Zhou, S. (2009). Study on the Reaction Degree of Calcined Coal Gangue Powder in Blended Cement by Selective Solution Method. Proced. Earth Planet. Sci. 1, 634-639. doi:10.1016/j.proeps.2009.09.100

Zunino, F., and Lopez, M. (2016). Decoupling the Physical and Chemical Effects of Supplementary Cementitious Materials on Strength and Permeability: A MultiLevel Approach. Cement and Concrete Composites 65, 19-28. doi:10.1016/ j.cemconcomp.2015.10.003

Conflict of Interest: XZ and WS were employed by China Western Construction Academy of Building Materials Co., Ltd. WY was employed by China West Construction Group Co., Ltd.

The remaining author declares that the research was conducted in the absence of any commercial or financial relationships that could be construed as a potential conflict of interest.

Publisher's Note: All claims expressed in this article are solely those of the authors and do not necessarily represent those of their affiliated organizations, or those of the publisher, the editors and the reviewers. Any product that may be evaluated in this article, or claim that may be made by its manufacturer, is not guaranteed or endorsed by the publisher.

Copyright (c) 2022 Zhu, Guo, Yang and Song. This is an open-access article distributed under the terms of the Creative Commons Attribution License (CC BY). The use, distribution or reproduction in other forums is permitted, provided the original author(s) and the copyright owner(s) are credited and that the original publication in this journal is cited, in accordance with accepted academic practice. No use, distribution or reproduction is permitted which does not comply with these terms. 